\title{
Capacidade antioxidante e triagem farmacológica de extratos brutos de folhas de Byrsonima crassifolia e de Inga edulis
}

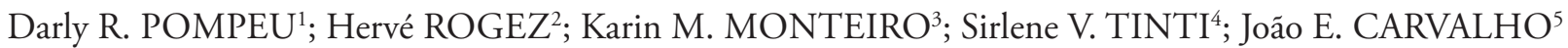

\begin{abstract}
RESUMO
Com o objetivo de avaliar o efeito de duas espécies amazônicas em doenças relacionadas aos processos de oxidação, determinouse a capacidade antioxidante (método Oxygen Radical Absorbance Capacity), o teor de polifenóis totais (método Folin-Ciocalteu - PT), bem como os efeitos farmacológicos in vitro (efeito antiproliferativo) e in vivo (antinociceptivo, antiinflamatório, antiulcerogênico) dos extratos hidroalcoólicos (65:35; v/v; etanol:água) das folhas de Byrsonima crassifolia (BC) e Inga edulis (IE). Os extratos de BC e IE apresentaram elevada capacidade antioxidante $\left(1.422\right.$ e $694 \mu \mathrm{mol}$ de Trolox Equivalente $\mathrm{g}^{-1} \mathrm{de}$ folha seca - FS, respectivamente) e um valor relativamente alto de PT (35,93 e 24,50 mg Equivalente ácido gálico g ${ }^{-1} \mathrm{FS}$, respectivamente). Essa atividade antioxidante não teve relação direta com o teor de compostos fenólicos dos extratos, sugerindo a contribuição de outros grupos químicos nessa atividade. Em cultura de células tumorais humanas (nove linhagens), os extratos não apresentaram atividade antiproliferativa significante, com efeito citotóxico somente na concentração mais elevada. Em modelo de nocicepçáo induzida pelo calor (placa quente), o extrato de IE apresentou efeito antinociceptivo $(\mathrm{P}<0,05)$ após 30 (250 e $500 \mathrm{mg} \mathrm{kg}^{-1}$ ) e $60 \mathrm{~min}\left(125\right.$ e $\left.500 \mathrm{mg} \mathrm{kg}^{-1}\right)$ de sua administração oral. Nos modelos de inflamação houve somente redução do edema para IE na concentração de $500 \mathrm{mg} \mathrm{kg}^{-1}$. Os extratos das duas espécies reduziram as lesôes ulcerativas produzidas por etanol em até $84 \%(\mathrm{P}<0,05)$, sugerindo uma possível ligação com a atividade antioxidante observada e indicando a necessidade de estudos para a elucidação do mecanismo de ação envolvido.
\end{abstract}

PALAVRAS-CHAVES: Amazônia; Oxygen radical absorbance capacity; Polifenóis; Propriedades farmacológicas.

\section{Antioxidant capacity and pharmacologic screening of crude extracts of Byrsonima crassifolia and Inga edulis leaves}

\begin{abstract}
In order to evaluate the effect of two Amazonian species on chronic diseases linked with the oxidative processes, we performed antioxidant capacity analyses (Oxygen Radical Absorbance Capacity - ORAC and Folin-Ciocalteu - PT assays) and pharmacological effects in vitro (antiproliferative effect) and in vivo (antinociceptive, antiinflammatory, antiulcerogenic effects) for ethanolic extracts (65:35; v/v; ethanol:water) from Byrsonima crassifolia (BC) and Inga edulis (IE) leaves. Both BC and IE extracts showed high ORAC values (1,422 and $694 \mathrm{mmol}$ of Trolox equivalent/g of dry leaf, respectively) and high PT contents (35.93 and $24.50 \mathrm{mg} g a l l i c$ acid equivalent $\mathrm{g}^{-1}$ dry leaf, respectively). The ORAC values had no correlation with PT, suggesting the presence of other chemical groups in the antioxidant activity value. The two extracts did not present significant antiproliferative activity on nine lines of human tumor cells, and cytotoxic effect was detected only at the highest concentration. The antinociceptive effect was investigated using the hot plate test, and IE extract presented a longer latency $(\mathrm{P}<0.05) 30$ and $60 \mathrm{~min}$ after oral administration. The antiinflammatory activity was only observed at the highest concentration, suggesting that the antinociceptive effect observed was not due to the antiinflammatory effect. The extracts of both species reduced the ulcerative lesions produced by ethanol up to $84 \%(\mathrm{P}<0.05)$, suggesting a relation with the antioxidant capacity. More studies are necessary to elucidate the mechanisms of action involved on antiulcerative effects.
\end{abstract}

KEYWORDS: Amazonia; Oxygen radical absorbance capacity; Polyphenols; Pharmacological proprieties.

\footnotetext{
${ }^{1}$ Departamento de Tecnologia de Alimentos, Centro de Ciências Naturais e Tecnologia, Universidade do Estado do Pará e Centro de Valorização Agroalimentar de Compostos Bioativos da Amazônia. drpompeu@uepa.br

2 Faculdade de Engenharia de Alimentos, Universidade Federal do Pará e Centro de Valorização Agroalimentar de Compostos Bioativos da Amazônia. frutas@amazon.com.br

${ }^{3}$ Centro Pluridisciplinar de Pesquisas Químicas, Biológicas e Agronômicas, Universidade Estadual de Campinas. karin@cpqba.unicamp.br

${ }^{4}$ Centro Pluridisciplinar de Pesquisas Químicas, Biológicas e Agronômicas, Universidade Estadual de Campinas. tinti@cpqba.unicamp.br

${ }^{5}$ Centro de Pluridisciplinar de Pesquisas Químicas, Biológicas e Agronômicas e Departamento de Clínica Médica, Faculdade de Ciências Médicas, Universidade Estadual de Campinas carvalho@cpqba.unicamp.br
} 


\section{INTRODUÇÃO}

A biodiversidade amazônica é fonte de espécies vegetais potencialmente úteis para o desenvolvimento de medicamentos, alimentos funcionais e cosméticos. Diversas espécies são utilizadas popularmente para o tratamento das mais variadas afecçóes, necessitando de estudos aprofundados para comprovar suas indicaçóes. A exploraçáo racional destas espécies poderia contribuir para o desenvolvimento sustentável da regiâo (Souza et al. 2008). Entre estas espécies pode-se citar o murucizeiro, Byrsonima crassifolia (L) H.B. \& K., e o ingazeiro, Inga edulis Mart. (Silva et al. 2007b).

Byrsonima crassifolia (BC) é uma árvore tropical da família das Malpighiaceae amplamente distribuída nas Américas Central e do Sul (Martínez-Vázquez et al. 1999). Suas folhas e casca tem sido utilizadas na medicina tradicional para tratar tosses, desordens gastrointestinais, infecçôes ginecológicas e da pele (Heinrich et al. 1992) e picadas de cobra (Rastrelli et al. 1997). Estudos experimentais com folhas e casca desta espécie apontaram alta capacidade antioxidante do extrato hidroalcoólico (Silva et al. 2007a), efeitos espasmogênicos (Bejar e Malone 1993), atividade antiprotozoária (PerazaSánchez et al. 2007) e antiinflamatória (Maldini et al. 2009).

Inga edulis (IE) é da família das Leguminosae: Mimosoideae e é amplamente distribuída nas florestas secundárias tropicais das Américas Central e do Sul. Suas folhas são utilizadas na medicina tradicional como antiinflamatório e antidiarréico (Silva et al. 2007b). Silva et al. (2007a; 2007b) apontaram elevada capacidade antioxidante do seu extrato hidroalcoólico. Souza et al. (2008) apontaram alta capacidade antioxidante empregando diversos métodos químicos e bioquímicos, avaliando a proteção de lipoproteínas e de eritrócitos contra a oxidação induzida de diferentes formas. Estudos fitoquímicos identificaram parte dos compostos fenólicos presentes nos extratos de folhas de I. edulis (Souza et al. 2007; Dias et al. 2010).

Em virtude do seu uso medicinal tradicional e dos resultados publicados sobre estas espécies até o momento, este trabalho teve como objetivo relacionar a capacidade antioxidante dos extratos obtidos de folhas de $B$. crassifolia e I. edulis com o potencial farmacológico, por meio de uma triagem de atividades farmacológicas.

\section{MATERIAL E MÉTODOS}

\section{Material vegetal}

As folhas de B. crassifolia e I. edulis foram identificadas por um especialista em farmacognosia do Museu Botânico Emílio Goeldi (Belém - PA, Brasil). As mesmas espécies foram comparadas com exsicatas depositadas no Herbário do referido museu (MG 122249 e MG 0153192, respectivamente). As folhas das espécies foram coletadas no município de Belém (PA) e imediatamente transportadas ao Laboratório.

\section{Animais}

Foram utilizados ratos machos adultos (Rattus norvegicus), variedade Wistar albino, pesando entre 180 e $250 \mathrm{~g}$ e camundongos machos adultos (Mus musculus), variedade Swiss, pesando entre 25 e $30 \mathrm{~g}$. Os animais foram fornecidos pelo Centro Multidisciplinar para Investigação Biológica na Área da Ciência em Animais de Laboratório (CEMIB) da Universidade Estadual de Campinas (Unicamp) e utilizados nos experimentos após o período mínimo de sete dias de adaptação ao biotério, com ciclo de claro-escuro de 12 horas, temperatura ambiente $\left(20 \pm 2{ }^{\circ} \mathrm{C}\right)$, com água e ração $a d$ libitum.

\section{Preparação do extrato}

As folhas de B. crassifolia e I. edulis foram lavadas e cortadas em pequenos pedaços (aproximadamente $2 \mathrm{~cm}$ por $2 \mathrm{~cm}$ ). Em seguida foram secas a $55^{\circ} \mathrm{C}$ por $2 \mathrm{~h} 30$ min conforme otimizado por Silva et al. (2011) e moídas. Fez-se uma extração com solução hidroalcóolica (65:35; v/v; etanol:água) em quatro ciclos de $1 \mathrm{~h}$ a $60^{\circ} \mathrm{C}$ e na razáo soluto:solvente de 1:20 $(\mathrm{m} / \mathrm{v})$ (Silva et al. 2007a). O extrato foi filtrado, centrifugado a $27.000 \mathrm{~g}$ por $15 \mathrm{~min}$ a $4^{\circ} \mathrm{C}$. O sobrenadante foi coletado e concentrado sob baixa pressão a $45^{\circ} \mathrm{C}$ e ao abrigo da luz e, em seguida, liofilizado. $\mathrm{O}$ pó obtido foi estocado a $-20^{\circ} \mathrm{C}$ sob atmosfera de $\mathrm{N}_{2}$ até a realização das análises.

\section{Determinação dos compostos fenólicos totais e da capacidade antioxidante}

\section{Compostos fenólicos totais}

Utilizou-se o método espectrofotométrico de FolinCiocalteu (Singleton e Rossi 1965) descrito por Silva et al. (2007a). Os resultados foram expressos em miligrama de equivalente ácido gálico por grama de folha seca ( $\mathrm{mg} \mathrm{EAG} \mathrm{g}{ }^{-1}$ de FS).

\section{Capacidade antioxidante}

A capacidade antioxidante foi avaliada pelo método Oxygen Radical Absorbance Capacity (ORAC) em fluorímetro de microplaca (Microplate Fluorescence Reader, Bio-Tek Instruments, Winoosk, USA), utilizando-se a fluoresceína como molécula flourescente e previamente descrito por Silva et al. (2007b). A atividade antioxidante ORAC foi expressa em $\mu$ mole de equivalente Trolox por grama de folha seca $\left(\mu \mathrm{mol} \mathrm{ET} \mathrm{g}{ }^{-1}\right.$ de FS). 


\section{Testes farmacológicos}

\section{Atividade antiproliferativa}

Para a realização da triagem in vitro foram selecionadas as seguintes linhagens de células cancerígenas cedidas ao Centro de Pesquisas Químicas, Biológicas e Agrícolas da Universidade Estadual de Campinas pelo 'National Cancer Institute' (USA): UACC-62 (melanoma), MCF-7 (mama), NCI-ADR (mama com fenótipo de resistência a múltiplas drogas), 786-O (rim), NCI-460 (pulmão), PCO-3 (próstata), OVCAR-03 (ovário), HT-29 (cólon) e K-562 (leucemia linfóide). A avaliação da atividade antiproliferativa dos extratos brutos de $B$. crassifolia e I. edulis foi realizada segundo metodologia descrita por Monks et al. (1991) utilizando-se doxorrubicina como controle positivo. Para o teste de atividade, foram plaqueados $100 \mu \mathrm{L}$ de células em meio RPMI/SFB/gentamicina, em placas de 96 poços. As placas foram incubadas por $24 \mathrm{~h}$ a $37{ }^{\circ} \mathrm{C}$ em atmosfera contendo $5 \%$ de $\mathrm{CO}_{2}$. Depois desse período uma placa controle foi fixada por meio da adição de ácido tricloroacético para determinação da quantidade de células no momento da adição das drogas. Os extratos foram ensaiados nas concentraçóes de 0,25; 2,5; 25 e $250 \mu \mathrm{g} \mathrm{ES} \mathrm{mL}^{-1}$ e incubados por $48 \mathrm{~h}$. Em seguida, as placas foram coradas pela adiçáo de $50 \mu \mathrm{L}$ do corante protéico sulforrodamina B (SRB) a $0,4 \%$ (peso/volume), dissolvido em ácido acético a $1 \%$, e incubadas a $4^{\circ} \mathrm{C}$, durante $30 \mathrm{~min}$. $\mathrm{O}$ corante ligado às proteínas celulares foi solubilizado com uma soluçáo de Trizma Base na concentração de $10 \mu \mathrm{M}$ e pH 10,5 por 5 min em ultra-som. A leitura espectrofotométrica da absorbância foi realizada em $560 \mathrm{~nm}$ em um leitor de microplacas Versa Max (Molecular Devices, Sunnyvale, CA, USA).

\section{Atividade antinociceptiva}

A atividade antinociceptiva foi determinada por meio do teste de placa quente utilizando-se grupos de seis a oito camundongos Swiss. Os animais foram tratados por via oral com solução de $\mathrm{NaCl}\left(0,90 \% ; 10 \mathrm{~mL} \mathrm{~kg}^{-1}\right)$, controle negativo, com morfina $\left(30 \mathrm{mg} \mathrm{kg}^{-1}\right)$, controle positivo, ou com extratos de B. crassifolia e I. edulis $(125,250$ e $500 \mathrm{mg}$ ES $\mathrm{kg}^{-1}$ ). Após 30, 60, 90 e 120 min da administração os animais foram submetidos ao estímulo álgico em placa quente $\left(56,5 \pm 0,1^{\circ} \mathrm{C}\right)$, até que apresentassem reflexos dolorosos característicos de acordo com o método descrito por Woolfe e McDonald (1944).

\section{Atividade antiinflamatória}

Para determinação da atividade antiinflamatória foram utilizados os métodos de dermatite induzida por óleo de cróton (Tubaro et al. 1985) e edema de pata induzido por carragenina (Winter et al. 1962). Para a dermatite induzida por óleo de cróton foram utilizados grupos de seis camundongos Swiss tratados por via oral com solução de $\mathrm{NaCl}\left(0,90 \% ; 10 \mathrm{~mL} \mathrm{~kg}^{-1}\right)$, controle negativo, com dexametasona $\left(1 \mathrm{mg} \mathrm{kg}^{-1}\right)$, controle positivo, ou com extratos de B. crassifolia e I. edulis (125, 250 e $500 \mathrm{mg} \mathrm{ES} \mathrm{kg}^{-1}$ ). Para o edema de pata utilizaram-se grupos de seis ratos Wistar tratados por via oral com solução de $\mathrm{NaCl}$ $\left(0,90 \% ; 10 \mathrm{~mL} \mathrm{~kg}^{-1}\right)$, controle negativo, com indometacina (10 $\left.\mathrm{mg} \mathrm{kg}^{-1}\right)$, controle positivo ou com extratos de BC e IE $\left(125,250\right.$ e $\left.500 \mathrm{mg} \mathrm{ES} \mathrm{kg}^{-1}\right)$.

\section{Atividade antiulcerogênica}

Utilizou-se o modelo de indução de úlcera por etanol absoluto de acordo com a metodologia descrita por Robert (1979). Os animais estavam em jejum de $24 \mathrm{~h}$ com livre acesso à agua. Os grupos de seis ratos Wistar foram tratados por via oral com solução de $\mathrm{NaCl}\left(0,90 \% ; 10 \mathrm{~mL} \mathrm{~kg}^{-1}\right)$, controle negativo, carbenoxolona (200 $\left.\mathrm{mg} \mathrm{kg}^{-1}\right)$, controle positivo, ou com extratos de B. crassifolia e I. edulis $(125,250$ e $500 \mathrm{mg}$ ES $\mathrm{kg}^{-1}$ ) e após $60 \mathrm{~min}$ todos os animais receberam $1 \mathrm{~mL}$ de etanol absoluto por via oral. Após $60 \mathrm{~min}$ da administração os animais foram sacrificados por deslocamento cervical. A contagem das lesôes e o cálculo do índice de lesão ulcerativa (ILU) foi feito de acordo com o método descrito por Bighetti et al. (2005).

\section{Análises estatísticas}

Os dados obtidos experimentalmente foram tratados por meio de análise de variância (ANOVA) utilizando-se o software STATISTIC for Windows 7.1 (STAT-SOFT), considerando-se os níveis de significância de 95\% (P<0,05), 99\% ( $\mathrm{P}<0,01)$ e 99,9\% ( $\mathrm{P}<0,001)$. Em seguida fez-se a comparação pelo Teste de Duncan utilizando-se o mesmo nível de significância.

\section{RESULTADOS E DISCUSSÃO}

\section{Capacidade antioxidante}

$\mathrm{Na}$ Tabela 1 são apresentados os teores de compostos fenólicos totais e a capacidade antioxidante ORAC encontrados nos extratos em pó obtidos das folhas de $B$. crassifolia e $I$. edulis. Os teores em compostos fenólicos totais encontrados neste trabalho para a $B$. crassifolia ficaram abaixo do encontrado por outros autores, enquanto que o $I$. edulis ficou dentro da faixa. Estas diferenças possivelmente estão relacionadas com o método de extração, purificação e a forma de expressar os resultados pelos autores. Silva et al. (2007b) utilizaram uma mistura de solventes (metanol, etanol, água destilada e ácido clorídrico; 69:20:10:1, v:v:v:v) a temperatura ambiente $\left(-28{ }^{\circ} \mathrm{C}\right)$ durante $24 \mathrm{~h}$, os autores expressaram seus resultados em massa de folha fresca (a umidade dessas folhas é de aproximadamente 50\% segundo Silva et al. 2010). Silva et al. (2007a) otimizaram a extração 
Tabela 1- Teores de polifenóis totais e atividade antioxidante ORAC (Oxygen radical absorbance capacity) dos extratos brutos de Byrsonima crassifolia e do Inga edulis

\begin{tabular}{|c|c|c|c|c|}
\hline \multicolumn{4}{|c|}{ Espécie } & \multirow{3}{*}{ Fonte } \\
\hline \multicolumn{2}{|c|}{ B. crassifolia } & \multicolumn{2}{|c|}{ I. edulis } & \\
\hline Fenólicos totais (mg EAG g ${ }^{-1}$ ) & ORAC $\left(\mu \mathrm{mol} \mathrm{ET} \mathrm{g}{ }^{-1}\right)$ & Fenólicos totais ( $\mathrm{mg} \mathrm{EAG} \mathrm{g}^{-1}$ ) & ORAC $\left(\mu \mathrm{mol} \mathrm{ET} \mathrm{g}{ }^{-1}\right)$ & \\
\hline 35,93 (FS) & 1.422 (FS) & 24,50 (FS) & 694 (FS) & \\
\hline 45,50 (FF) & 778,80 (FF) & 9,80 (FF) & 239,50 (FF) & Silva et al. (2007b) \\
\hline- & - & 125,30 (ES) & - & Silva et al. (2007a) \\
\hline 58,10 (FS) & 736 (FS) & 44,20 (FS) & 1.463 (FS) & Souza et al. (2008) \\
\hline \multirow[t]{2}{*}{-} & - & 496,50 (ESP) & 11.160 (ESP) & Souza et al. (2007) \\
\hline & & 378,9 (ESP) & 8.313 (ESP) & Dias et al. (2010) \\
\hline
\end{tabular}

FS: Folha Seca; ES: Extrato bruto Seco; FF: Folha Fresca; ESP: Extrato Seco Purificado por SPE; EAG: Equivalente de Ácido Gálico; ET: Equivalente Trolox.

de compostos fenólicos de folhas de I. edulis, com soluçáo hidrolacóolica $(86,8 \%)$ a $58,2^{\circ} \mathrm{C}$ por 46 min 48 seg. Souza et al. (2007) utilizaram solução hidrometanólica (50:50; v:v) durante $1 \mathrm{~h}$ a temperatura ambiente. Neste estudo, os autores identificaram o acido gálico, a catequina, a epicatequina, a miricetina-3-ramnopiranosídeo, a quercetina3-glucopiranosídeo e a quercetina-3-ramnopiranosídeo. Souza et al. (2008) utilizaram solução hidrometanólica (80:20 $\mathrm{v} / \mathrm{v})$ durante $3 \mathrm{~h}$ a temperatura ambiente. Dias et al. (2010) utilizaram uma mistura de solventes (acetona:água:ácido acético; 70:28:2; v:v:v), durante $2 \mathrm{~h}$ sob agitação constante, à temperatura ambiente, um total de três ciclos de extraçáo. Os autores identificaram e quantificaram neste trabalho os seguintes compostos fenólicos: ácido gálico, procianidina $\mathrm{B}_{1}$, catequina, procianidina $\mathrm{B}_{2}$, epicatequina, delfinidina, cianidina, miricetina-3-o- $\alpha-\mathrm{L}-\mathrm{ramnopiranosídeo,} \mathrm{quercetina-}$ 3-o- $\alpha$-L-ramnopiranosídeo, miricetina e quercetina.

\section{Efeitos farmacológicos}

\section{Atividade antiproliferativa}

Os extratos brutos das folhas de B. crassifolia e de I. edulis foram submetidos à avaliação da atividade antiproliferativa em culturas de células tumorais humanas de nove tipos. $\mathrm{Na}$ Figura 1 pode-se observar que esses extratos brutos náo possuem atividade antiproliferativa, pois foi observado efeito somente na concentração mais elevada. Os compostos fenólicos, em especial os flavonóides, podem ter efeito quimiopreventivo, neutralizando radicais livres com potencial mutagênico (Middleton et al. 2000; Yang et al. 2001). No entanto após o desenvolvimento do câncer são pouco eficazes, pois não atuam nos processos de proliferaçáo e morte celular (Ferguson et al. 2004).

\section{Atividade antinociceptiva}

Para avaliar um possível efeito antinociceptivo dos extratos obtidos das folhas de B. crassifolia e I. edulis, foi realizado o
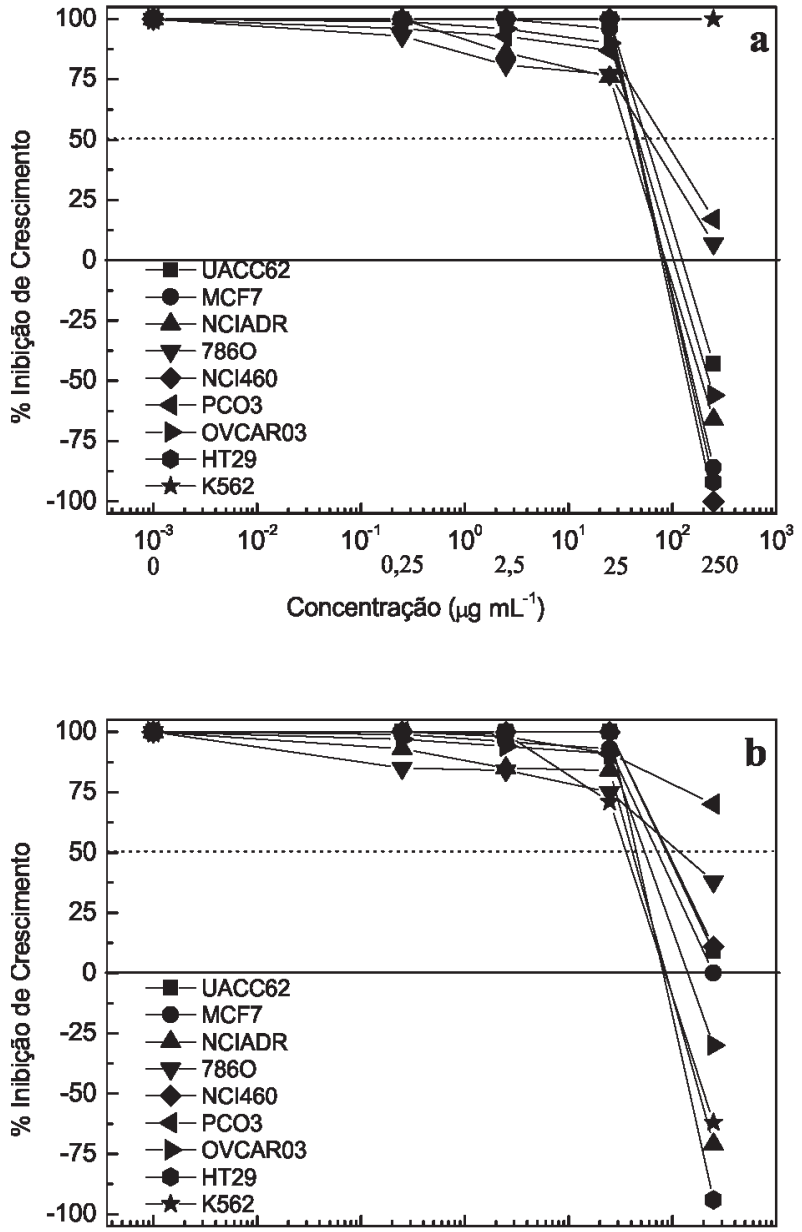

Figura 1 - Efeito da inibição do crescimento de células tumorais humanas em diferentes concentrações de extratos brutos de Byrsonima crassifolia (a) e Inga edulis (b). Linhagem de células cancerígenas: UACC-62 (melanoma), MCF-7 (mama), NCl-ADR (mama com fenótipo de resistência a múltiplas drogas), 786-0 (rim), NCl-460 (pulmão), PCO-3 (próstata), OVCAR-03 (ovário),, HT-29 (cólon) e K-562 (leucemia linfóide) 
teste de nocicepçáo induzida por calor (placa quente). O controle positivo, a morfina, aumentou significativamente o tempo de reação dos animais em todos os tempos testados. O extrato de $B$. crassifolia aumentou o tempo de reação ao estímulo nociceptivo após $120 \mathrm{~min}$ da administraçáo oral somente na maior dose $\left(500 \mathrm{mg} \mathrm{kg}^{-1}\right)$ (Figura 2a). Para o extrato bruto de I. edulis (Figura 2b) observou-se aumento do tempo de reação dos animais para as diferentes doses utilizadas e nos tempos de 30 e 60 minutos, demonstrando indícios claros de atividade antinociceptiva de curta duração, pois em
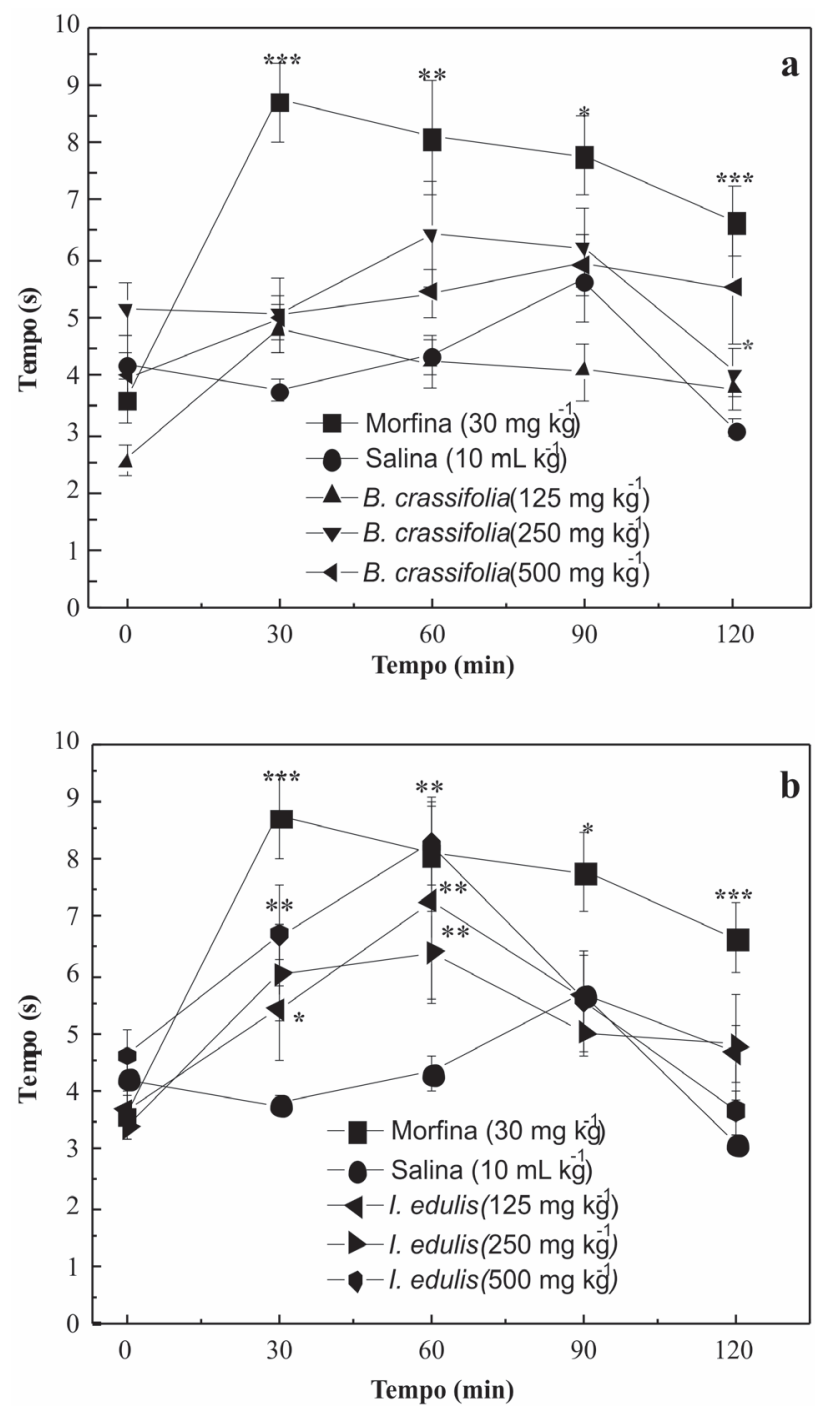

Figura 2 - Reação ao estímulo térmico de ratos tratados com extrato bruto de Byrsonima crassifolia (a) ou Inga edulis (b). Os valores expressam as médias seguidas de seus respectivos desvios padrão. ANOVA: Basal: $F(7,44)=3,73$ $P>0,01 ; 30$ min: $F(7,44)=6,49 P<0,001 ; 60 \mathrm{~min}: F(7,44)=3,36 P>$ 0,01; 90min: $F(7,44)=2,73 P>0,05 ; 120$ min: $F(7,44)=4,35 P>0,001$. Teste de Duncan: ${ }^{*} P<0,05 ;{ }^{* \star P} P<0,01 ;{ }^{* * *} P<0,001$. nenhum dos casos a atividade foi superior a $60 \mathrm{~min}$. O efeito sobre o processo doloroso pode ser consequência de uma açáo central, por bloqueio da condução do estímulo doloroso, como o produzido pela morfina ou por uma ação antiinflamatória. $\mathrm{O}$ método da placa quente tem maior especificidade para a atividade antinociceptiva de drogas que atuam no sistema nervoso central, como os analgésicos narcóticos. No entanto drogas com atividade antiinflamatória também podem reduzir a dor na presença de inflamaçấo. Para um possível efeito antiinflamatório, os extratos foram avaliados em modelo de inflamaçâo de pata induzida pela carragenina e no modelo de edema de orelha produzido por óleo de cróton (Fernandes 2002). Além disso, como o processo inflamatório gera muitos radicais livres os modelos de edema são muito úteis para avaliar in vivo a ação de antioxidantes.

\section{Atividade antiinflamatória}

No modelo de edema de pata induzido pela carragenina os extratos das duas espécies não produziram diminuição do edema nas doses utilizadas $\left(125,250\right.$ e $\left.500 \mathrm{mg} \mathrm{kg}^{-1}\right)$.

No edema de orelha induzido pelo óleo de cróton, o extrato bruto da $B$. crassifolia também não produziu efeito (Figura 3a). Todavia o extrato bruto de I. edulis produziu diminuição significativa do edema $(\mathrm{P}<0,05)$ somente na dose de $500 \mathrm{mg} \mathrm{kg}^{-1}$ (Figura 3b) quando comparada com o grupo controle (solução salina). Assim, em razão dos resultados nesses modelos de inflamação, é pouco provável que a atividade antinociceptiva observada em placa quente esteja relacionada a um efeito antiinflamatório, mas sim por atividade no sistema nervoso central. No entanto, é pouco provável que os polifenóis sejam os responsáveis por essa atividade antinociceptiva, pois em virtude de sua elevada polaridade dificilmente conseguiriam penetrar no sistema nervoso central para exercer essa atividade. Certamente as substâncias responsáveis pelo efeito antinociceptivo deverão ser identificadas nas fraçôes com menor polaridade nesses extratos.

Braggio et al. (2002) utilizaram suco liofilizado de

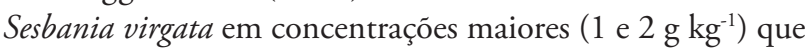
as utilizadas neste trabalho e diminuíram o edema de orelha em camundongos de 58 e $61 \%$, respectivamente.

\section{Atividade antiulcerogênica}

O etanol é considerado um agente irritante da mucosa gástrica por destruir a camada de muco e o bicarbonato, que atuam na proteção da mucosa gástrica contra o ácido clorídrico e outros agentes agressores. O bloqueio da citoproteção gástrica é consequência da precipitação de proteínas, liberação de radicais livres e redução da concentraçáo de compostos sulfidrilas nas células da mucosa (Pacheco et al. 2006), por isso é utilizado como um modelo de indução a úlcera. $\mathrm{Na}$ Figura 4 apresentam-se os efeitos dos extratos brutos de 

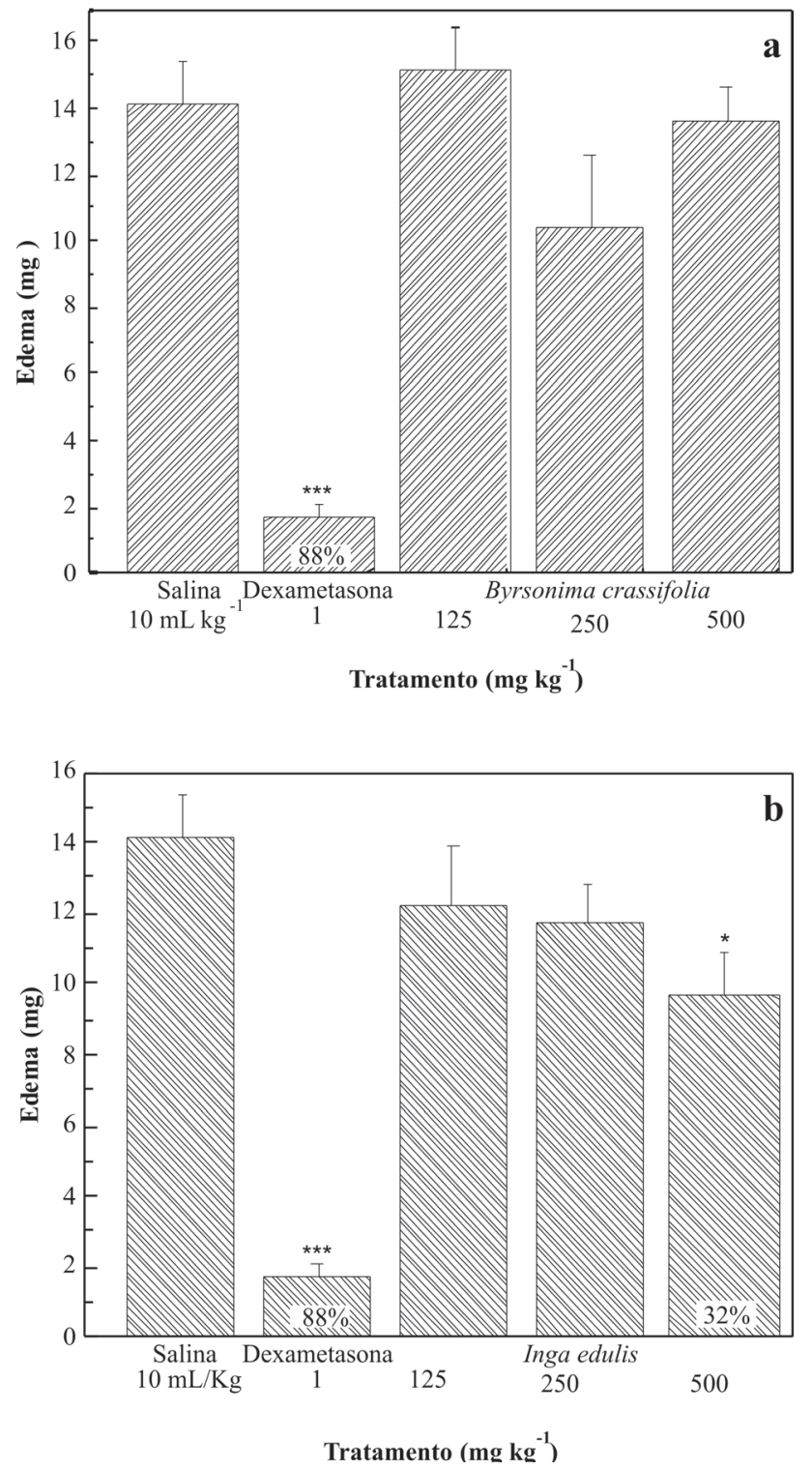

Figura 3 - Efeito da administração oral de extrato bruto de Byrsonima crassifolia e Inga edulis em camundongos utilizando o modelo de dermatite induzida por óleo de cróton. Os resultados expressam as médias seguidas de seus respectivos desvios padrão. ANOVA: $F(4,24)=17,68 P<0,001$. Teste de Duncan: ${ }^{*} \mathrm{P}<0,05$; ${ }^{* *} \mathrm{P}<0,01$; ${ }^{* *} \mathrm{P}<0,001$

B. crassifolia (a) e I. edulis (b) neste modelo de indução de úlcera. Pode-se observar que as duas espécies produziram diminuição dos danos ulcerativos nos animais tratados, com dependência em relação às doses. No caso de $B$. crassifolia houve uma estabilização das lesôes ulcerativas nas doses de 250 e $500 \mathrm{mg} \mathrm{kg}^{-1}$. Este mesmo extrato apresentou os melhores resultados de diminuiçấo das lesôes ulcerativas estudadas neste trabalho. Os resultados obtidos para a $B$. crassifolia neste modelo de lesão ulcerativa foram melhores
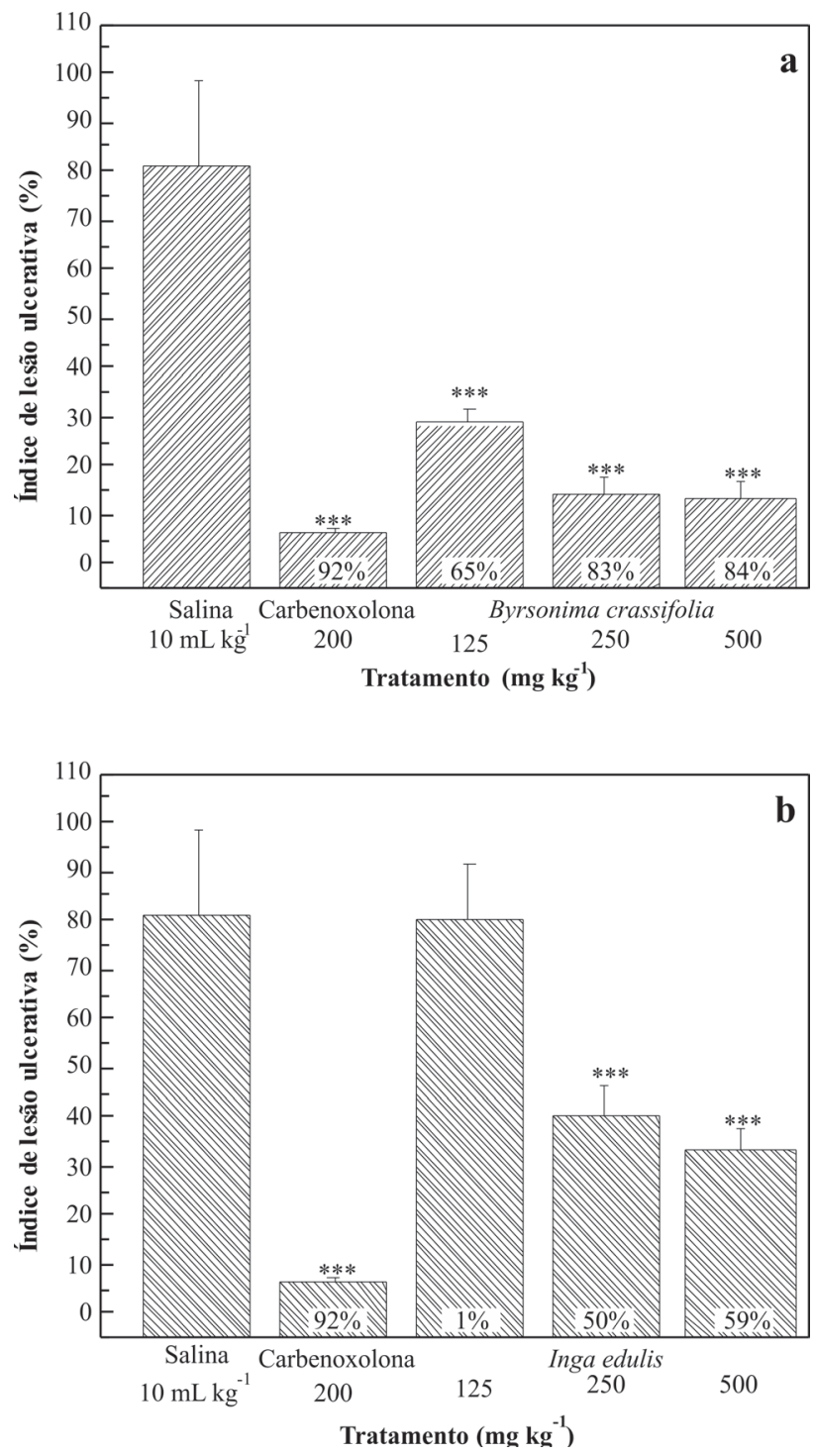

Figura 4 - Efeito da administração oral de extrato de Byrsonima crassifolia (a) e Inga edulis (b) em úlcera gástrica induzida por etanol em ratos. Os resultados expressam as médias seguidas de seus respectivos desvios padrão. ANOVA: $F(7,31)=15,83 P<0,001$; Teste de Duncan: ${ }^{*} P<0,001$.

que aqueles encontrados por Dias et al. (2000) utilizando extrato de Rosmarinus officinalis e Pacheco et al. (2006) utilizando hidrolisado de proteínas de soro de leite. Muitos polifenóis, especialmente os taninos, são frequentemente responsáveis pelos efeitos antiulcerogênicos de diversos extratos vegetais (Carvalho 2006). Portanto, é provável que os polifenóis presentes nessas espécies sejam pelo menos em parte responsáveis pelos efeitos antiulcerogênicos.

A próxima etapa desse projeto deverá estudar se o mecanismo de açáo dessa atividade anitulcerogênica pode 
estar relacionado com a diminuição da produção de ácido ou com fatores citoprotores como aumento da produção de muco, radicais sulfodrilas, óxido nítrico e fatores relacionados com a cicatrização.

\section{CONCLUSÕES}

Com base nos resultados apresentados pelos extratos brutos de folhas de B. crassifolia e I. edulis demonstrou-se que as duas espécies possuem elevado teor de compostos fenólicos e alta capacidade antioxidante, com elevado potencial farmacológico com destaque para a atividade antiulcerogênica. Apesar de outros trabalhos apontarem para os flavonóides como os principais grupos responsáveis pela elevada capacidade antioxidante, e consequentemente dos efeitos farmacológicos, mais estudos são necessários a fim de esclarecer quais são os compostos responsáveis por estes efeitos.

\section{AGRADECIMENTOS}

Os autores são gratos ao Conselho Nacional de Desenvolvimento Científico e Tecnológico, ao Instituto Internacional de Educação do Brasil, a Coordenação de Aperfeiçoamento de Pessoal de Nível Superior e as equipes técnicas e científicas do Laboratório de Farmacologia e Toxicologia do Centro Pluridisciplinar de Pesquisas Químicas, Biológicas e Agrícolas (CPQBA) e da Usina de Alimentos da Universidade Federal do Pará (UFPA).

\section{BIBLIOGRAFIA CITADA}

Bejar, E.; Malone, M.H. 1993. Pharmacological and chemical screening of Byrsonima crassifolia, a medicinal tree from Mexico. Part I. Journal of Ethnopharmacology, 39: 141-158.

Bighetti, A.E.; Antonio, M.A.; Kohn, L.K.; Rehder, V.L.G.; Foglio, M.A.; Possentti, A.; Vilela, L.; Carvalho, J.E. 2005. Antiulcerogenic activity of a crude hydroalcoholic extract and coumarin isolated from Mikania laevigata Schultz Bip. Phytomedicine, 12: 72-77.

Braggio, M.M.; Lima, M.E.L.; Veasey, E.A.; Haraguchi, M. 2002. Pharmacological activities of leaves from Sesbania virgata (Cav.) Pers. Arquivos do Instituto de Biologia, 69: 49-53 (in Portuguese, with abstract in English).

Carvalho, J.E. 2006. Antiulcerogenic and anticancer activities of the natural and synthetic products. Multiciência, 7: 1-18 (in Portuguese).

Dias, A.L.S.; Souza, J.N.S.; Rogez, H. 2010. Purification of phenolic compounds from Inga edulis leaves using solid-phase extraction: major compounds quantification and antioxidant capacity evaluation. Quimica Nova, 33: 38-42 (in Portuguese, with abstract in English).

Dias, P.C.; Foglio, M.A.; Possenti, A.; Carvalho, J.E. 2000. Antiulcerogenic activity of crude hydroalcoholic extract of Rosmarinus officinalis L. Journal of Ethnopharmacology, 69: 57-62.
Fernandes, A.T. 2002. Pharmacology activity of extracts obtained from Plathymenia reticulata BENTH. (Leguminosae). Dissertação de Mestrado em Clínica Médica, Unicamp-FCM, 143 pp. (in Portuguese).

Ferguson, D.; Philpott, M.; Waeg, G.; Striegl, G.; Jurgens, G. 2004. Dietary cancer and prevention using antimutagens. Toxicology, 198 (1-3): 147-159.

Heinrich, M.; Rimpler, H.; Barrera, N. 1992. Indigenous phytotherapy of gastrointestinal disorders in a lowland Mixe community (Oaxaca, Mexico): ethnopharmacologic evaluation. Journal of Ethnopharmacology, 36: 63-80.

Maldini, M.; Sosa, S.; Montoro, P.; Giangaspero, A.; Balick, M.J.; Pizza, C.; Della Loggia, R. 2009. Screening of the topical antiinflammatory activity of the bark of Acacia cornigera Willdenow, Byrsonima crassifolia Kunth, Sweetia panamensis Yakovlev and the leaves of Sphagneticola trilobata Hitchcock. Journal of Ethnopharmacology, 122: 430-433.

Martínez-Vásquez, M.; González-Esquinica, A.R.; Cazares Luna, M.; Moreno Gutiérrez, M.N.; Garcia Argáez, A.N. 1999. Antimicrobial activity of Byrsonima crassifolia (L.) H.B.K. Journal of Ethnopharmacology, 66: 79-82.

Middleton, E.; Kandaswami, C.; Theoharides, T.C. 2000. The effects of plant flavonoids on mammalian cells: Implication for inflammation, heart disease, and cancer. Pharmacology Reviews, 52: 673-751.

Monks A.; Scudiero D.; Skehan, P.; Shoemaker, R.; Paull, K.; Vistica, D.; Hose, C.; Langley, J.; Cronise, P.; Vaigro-Wolff, A.; Gray-Goodrich, M.; Campbell, H.; Mayo, J.; Boyd, M. 1991. Feasibility of a high-flux anticancer drug screen using a diverse panel of cultured human tumor cell lines. Journal of the National Cancer Institute, 83: 757-766.

Pacheco, M.T.B.; Bighetti, E.; Antônio, M.; Carvalho, J.E.; Rosaneli, C.F. Sgarbieri, V.C. 2006. Effects of a whey protein concentrate and it's peptides in the protection of ulcerative lesions at rat gastric mucosa. Revista de Nutrição, 19: $47-55$ (in Portuguese, with abstract in English).

Peraza-Sánchez, S.R.; Cen-Pacheco, F.; Noh-Chimal, A.; May-Pat, F.; Simá-Polanco, P.; Dumonteil, E.; García-Miss, M.R.; MutMartín, M. 2007. Leishmanicidal evaluation of extracts from native plants of the Yucatan peninsula. Fitoterapia, 78: 315-318.

Rastrelli, L.; De Tommasi, N.; Berger, I.; Caceres, A.; Saravia, A.; De Simone, F. 1997. Glycolipids from Byrsonima crassifolia. Phytochemistry, 45: 647-650.

Robert A. 1979. Cytoprotection by prostaglandins. Gastroenterology, 77: 761-767.

Silva, E.M.; Rogez, H.; Larondelle, Y. 2007a. Optimization of extraction of phenolics from Inga edulis leaves using response surface methodology. Separation and Purification Technology, 55: 381-387.

Silva, E.M.; Souza, J.N.S.; Rogez, H.; Rees, J.F.; Larondelle, Y. 2007b. Antioxidant activities and polyphenolic contents of fifteen selected plant species from the Amazonian Region. Food Chemistry, 101: 1012-1018. 
Silva, E.M.; Silva, J.S.; Pena, R.S.; Rogez, H. 2011. A combined approach to optimize the drying process of flavonoid-rich leaves (Inga edulis) using experimental design and mathematical modelling. Food and Bioproducts Processing, 89: 39-46.

Souza, J.N.S.; Silva, E.M.; Loir, A.; Rees, J.F.; Rogez, R. Larondelle, Y. 2008. Antioxidant capacity of four polyphenol-rich Amazonian plant extracts: A correlation study using chemical and biological in vitro assays. Food Chemistry, 106: 331-339.

Souza, J.N.S.; Silva, E.M.; Silva, M.N.; Arruda, M.S.P.; Larondelle, Y.; Rogez, H. 2007. Identification and antioxidant activity of several flavonoids of Inga edulis leaves. Journal of the Brazilian Chemical Society, 18: 1276-1280.
Tubaro, A.; Dri, P.; Delbello, G.; Zilli, C.; Loggia, R.D. 1985. The cróton oil ear test revisited. Agents and Actions, 17: 347-349.

Winter, C.A.; Risley, E.A.; Nuss, G.W. 1962. Carregeenin induced edema in the hind paw of the rat as an assay for antiinflamatory drugs. Proceedings of the Society for Experimental Biology and Medicine, 3: 544-547.

Woolfe, G.; Macdonald, A.D. 1944. The evaluation of the analgesic action of pethidine hydrochloride. Journal of Pharmacology and Experimental Therapeutics, 80: 300-3007.

Yang, C.S.; Landau, J.M.; Huang, M.T.; Newmark, H.L. 2001. Inhibition of carcinogenesis by dietary polyphenolic compounds. Annual Review of Nutrition, 21: 381-406.

Recebido em 18/10/2010

Aceito em 11/04/2011 